\title{
Approaches to Creating a VR Course for Adapting Students to the University Corporate Culture
}

\author{
Chernysheva T.L.
}

\author{
Novosibirsk State Technical University, Novosibirsk, Russia \\ Email: tablack@mail.ru
}

\begin{abstract}
The article substantiates the thesis about the consistency of combining traditional education and the so-called digital, that is, based on the use of innovative digital technologies in the educational process. It is proved that modern students need positive experiences related to obtaining knowledge, trust, reputation and involvement are needed. The sense of presence in the moment is created by VR technologies that affect almost all channels of human perception of information. They eliminate one of the main deficits of modern students, attention deficit. The aim of the work is to find approaches to create a VR course with the aim of adapting freshmen to the corporate culture of the university, which is able in a very short time to create an impression and attitude, commitment to their university, create its competitive image.
\end{abstract}

Keywords: digital economy, VR-technologies, adaptation, university corporate culture, socially significant

skills

\section{CHALLENGE FOR INTEGRATION OF TRADITIONAL AND DIGITAL EDUCATION AT THE AGENDA OF UNIVERSITIES}

Today, education is a continuous multi-component process in changing conditions. The former principles of education in the era of the digital economy cannot but undergo a transformation. The information society dictates new rules for gaining knowledge. The lecture and seminar form did not fail during times of information deficit when there is a glut of information, innovative educational technologies are needed. The construction of the educational process should be based on the integration of digital educational tools and systems. Gradually, a new pedagogical paradigm will be formed, based on classical values and educational goals, but with the use of digitalization. The right choice would be to design the educational process according to the blended learning model, when training is conducted through various channels - through mass open online access platforms, all kinds of online cloud resources, and problem lectures, as well as laboratory and practical studies, are carried out on the premises of the universities themselves, and laboratory and practical work is underway project activities, round tables are held to discuss current issues [1] Curricula should be largely developed taking into account requests and requirements. of the identities of the students themselves. Online testing will allow you to identify individual profiles of competencies that can be adapted to the capabilities and abilities of students, creating unique educational paths for them. Over time, digital technology will change both the tasks themselves and the forms, as well as how to accomplish them, providing ever new tools for data processing. The process of gaining knowledge will increasingly depend on technological innovation. The functions of the teacher will also change dramatically: this will not be the translation of knowledge, but help in finding your own niche, motivation for learning, transferring skills, mentoring. The main purpose of the teacher will be to help in life selfdetermination, which seems much more complicated and important than the translation of knowledge, and also requires special skills. In order to remain competitive, the teacher needs to create dynamic content of his own discipline, introduce digital tools into it, that is, use various means of interactive interaction and assessment (tag cloud, real-time polls), use all kinds of visualization resources when contacting the audience e.g. tilda, landing pages, storytelling, etc.

The broadcast of theoretical knowledge will be undertaken by competently selected video content by teachers, electronic simulators, game developing multiplayer games, interactive educational platforms, educational social networks and web pages [2].

Visual products will play an increasing role in the process of conveying knowledge and information. Visualization of educational material in the advanced present and in the future is animation, graphic images, dynamic tables, graphs, infographics, on-screen digital maps, projection models on the entire wall, digital glasses, holography, neuroinformatics, retinal screens. Cloud technology will enable comfortable remote work on projects along with other participants. The involvement of game elements in 
the educational process should become a widely used practice, entailing the introduction of a system of achievements, points, points, levels, insignia for each educational module, similar to how a computer game is divided into sessions, periods, levels, etc. More and more artificial intelligence will be introduced into the educational process. An individual digital teacher in online learning environments will be able to imitate a real interlocutor who determines the level of preparedness of a student. There will be electronic teachers on the smartphone. The abilities of a young person will also be determined using special career guidance tests, the results of which will allow for the individual selection of subjects. Under the characteristics of the student will be selected individual literature based on neural networks. In educational activities, smart educational devices interactive whiteboards and tablets in laboratories devices for augmented reality, smart glasses, a sensory model, a camera, an LED display, smartphones and glasses for conducting classes in virtual space [3] will find application.

\section{VR POTENTIAL IN THE EDUCATIONAL PROCESS}

The world is very actively conducting research in the field of virtual reality in the field of education, as evidenced by the number of fresh foreign publications that address the use of VR to solve completely different educational problems in different fields of knowledge. This includes language training, entrepreneurship, architecture and even music. Especially a lot of work aimed at building the skills of future medical workers $[4,5,6]$.

Not only foreign commercial enterprises but also domestic ones are actively mastering work with VR content in order to educate their employees. It is obvious that universities will also resort to VR technologies since their educational potential is very high. The amount of knowledge about the world around us is constantly increasing, and it will be algorithmized, embodied in interactive forms.

Virtual reality is a computer-generated three-dimensional environment with which the user can interact completely immersed in it. The features of virtual reality are that it supports the user's sense of the reality of what is happening, provides interaction with the environment, provides the opportunity to explore the world in great detail, involves both the brain and the body of the user, affecting the maximum possible number of senses. Nobody thinks for the student, the student rethinks all the perceived information [7].

VR with the effect of full immersion implies the presence of three factors: 1) simulation of the world with a high degree of detail, 2) recognition of user actions and reactions to them in real-time, 3) the presence of a powerful computer, to which special equipment is attached, providing the effect of immersion in the process environmental studies.
Incomplete immersion in alternative reality includes simulations with high-quality images, sound, and controllers, broadcast on a widescreen [8].

Virtual reality is an artificial environment that puts the user directly in a certain experience where interaction with three-dimensional worlds takes place. The student interacts with them, imitating vision, hearing, touch, smell. As a rule, objects and situations are visualized that can only be seen in reality in emergency cases, for example, natural disaster conditions [9]. The most obvious application of VR technology in the study of exact and engineering sciences. With their help, it is possible to model, for example, physical experiments [10], experiments in the field of chemistry [11], mining [12].

VR eliminates the cost of testing in real time and space. In physics, for example, the effects of force, mass, trajectory, speed, and other characteristics on a particular object are analyzed, which allows it to be predicted for its behavior under various conditions. VR is conducive to exploring the molecular and atomic world, as well as the world of stars and galaxies.

Using VR products without the participation of developers was difficult until a special platform for the development and implementation of projects in virtual reality appeared, which helps simplify the process of developing and coordinating a project with a client. The platform works on drag-and-drop technology as a familiar computer interface and is controlled using a mouse or touch screen.

This platform allowed direct customers to make changes without special programming skills. This was made possible thanks to the visual programming language Blockly, which helps to build relationships between blocks of information: now both the objects themselves and interaction scenarios can be changed. Partially open code and an open library of locations and objects expand the capabilities of the platform to other developers [13].

Thus, the interactive interfaces of dynamic infographics have become a source of constantly updated information. The user converts the displayed content in accordance with his tasks. There is a plot and at the same time research logic of the presentation: the interactions man environment are modeled, any characteristics of the environment are set, a hardware assessment of human actions in the simulated situation is carried out. The values of VR can be called involvement, a call of strong emotions, the utmost concentration of attention. It is especially important for modern students who have significant difficulties concentrating on the object of cognition, solving the problem of attention deficit, since a person in a helmet is forced to go through all the locations to the end, he is tied to specific locations. The distance between employers and students will be reduced. Universities will subsequently be able to independently develop VR - courses on the formation of competencies of certain professions, as well as soft skills, in particular, on collective intelligence, team building. Collaboration with the effect of presence with the help of working and educational 3D spaces will be in demand. Simultaneous interaction in the community and complete immersion is 
the most important direction in the development of VR at the present time.

\section{THE ROLE OF VR IN ADAPTATION OF STUDENTS TO THE UNIVERSITY CORPORATE CULTURE}

Today it is impossible to deny that the effectiveness of traditional means of transmitting knowledge and influencing youth for educational purposes, such as lectures, seminars, thematic classes, evenings, and even festivals, is extremely low. The guys understand that, as a rule, these events have a "reporting", formal character. Non-standard creative technologies will be in demand by modern youth, the indispensable condition of which is involvement of children in interesting and meaningful action as direct organizers and performers, and virtual reality technologies provide such an opportunity. They allow you to create an environment that is perceived by a person through the sensory organs, imitate both the effect and the reaction to the effect, therefore they are capable of generating vivid emotions in participants in real time.

Virtual reality objects usually behave similarly to the behavior of similar non-virtual reality objects. The user acts on them in accordance with the well-known laws of gravity, reflection, hydro and aerodynamics.

At the moment, the efforts of domestic developers of VR courses are focused more not on the construction of the worlds of the branches of science, but on the creation of training content in those practical activities that are characterized by clear algorithms, for example, extinguishing a fire, actions of rescuers in a disaster area, controlling an airplane, submarine or helicopter, parachuting, oil production, steel melting. However, corporate VR-training in the areas most often associated with increased risk is starting to become popular. VR technologies are used in industry, where they can be used to simulate and practice many emergency situations in high-tech industries, provide training on the operation of expensive equipment, and work out emergency procedures [14]. However, trainings are already being developed to build effective sales skills and communicate with difficult customers.

In our opinion, VR technologies have a huge potential for the development of precisely socially significant human qualities, empathy.

In this regard, of course, over time, VR will be used for educational purposes, the formation of soft skills, and adaptation. We suggest considering the use of VR in order to adapt students to the corporate culture of the university. Obviously, students from different universities of the country, and universities of the same city are different, and they are distinguished by the basic level of corporate culture, certain deep-seated attitudes that arise among members of the same community on the basis of personal patterns, supported by the experience of joint actions. It is necessary to strengthen positive attitudes and work to eliminate negative ones. Including this can be achieved through targeted activities to adapt students to the values and lifestyle of their new academic community. The university is very important for the formation of freshman qualities in areas consistent with the corporate culture of the university. It is necessary to develop behavioral skills at the university without talking about the norms and rules, but integrating these norms and rules into typical situations of university life and provoking students to find the right way out of them. Examples are how to use a campus card, how to order books from a university research library, how to enroll in a sports or dance section, book a place in a dispensary, etc. Students will get acquainted with the university, with its rich resources and capabilities, by teaching the correct functioning algorithms on its territory. A university is usually a city in a city, so it includes almost all the structures that exist in a large city (authorities, security, law, finance, food, the culture club, sports facilities, etc.), therefore, they will turn into a location of a kind of theater of university values. On these virtual sites, the development of socially responsible behavior among students and new employees of the university will be carried out by modeling various life situations in which a choice of behavior becomes necessary. New approaches of the university public to education, to work, to people around them, to cultural heritage, to safety, to health conservation, to sports, to nature, to older people, etc.; emergency action skills will appear, in particular in a terrorist attack, in a fire, first aid skills.

Through VR, students will get exactly the experience of civilized behavior in the systems student - student, student - teacher, student-dean's office, student - university environment, once in the most typical situations for student life (conflict with the teacher in the classroom, procrastination in preparation for the exam, the choice of the topic of scientific work and the leader) that "revive" the techniques for developing the emotional intelligence necessary for successful studies at the university: selfawareness, motivation, self-regulation, empathy, mastery social skills. Participants are involved in miniperformances with their own activity, finding approaches to solving psychological problems [15].

As you progress through the levels for which, like a computer game, they get points, students form in their minds a concept of what a new university life is for them, which includes the ability to study at this particular university. What students will expect over the course of 46 years of study will be conveyed on the basis of specific situations that arise in everyday student life through dramatization. Both positive and negative solutions to problems will be shown, depending on the student's choice of behavior. Freshmen will understand that there is a whole group of skills hidden behind the concept of "learning", which includes, for example, the ability not only to listen but also to hear both your mentors and colleagues in the group, the ability to motivate yourself to be complex and not always interesting forms of work, the ability to take tests and exams "in flow", etc.

VR helps the formation of emotional thinking because the student is in a particular moment where he is forced to 
survive the consequences of a particular behavioral choice. The person does not get used to a certain role, does not imagine himself in the circumstances of various characters, but he himself is a direct participant in the action. As a result, the action participant will turn the proposed context into his own, as if he would appropriate this or that vital material, trying it on him- or herself. The person will live through strong emotions, which will correlate with the norms and rules of behavior in a new community for him. The VR adaptation course will become a powerful measure for the formation of university patriotism, which will lead to a much higher level of satisfaction with the quality of education among students and graduates and will affect the image of the university.

VR will facilitate involvement in various university activities, not only related to the chosen specialty, but also those that are aimed at creativity and self-realization; discover potential communication channels between teachers and students; will teach university rituals rooted in the history and traditions of the university; will contribute to the observance of uniform standards for the use of various university services (library, catering facilities, sports centers, cultural center, wardrobe, etc.). Responsible attitude to the educational process, to all forms of educational and extracurricular activities and initiatives developed within its framework should be formed from the very beginning of the student's stay in the university. VR course will give an idea not only about the history of the university, traditions, and rules that must be followed within its walls but also about the possibilities of inter-faculty interaction, the possibilities to create interdisciplinary projects within the framework of teamwork. Acquaintance with the sites of search research activities will be shown through the algorithm for preparing a report at the conference, submitting documents for the grant.

When working on creating a VR course, special attention should be paid to identifying the most typical situations that occur in student life at the university, since the rules of behavior in these situations need to be conveyed to freshmen. VR scenarios will be formed on the basis of technological maps, regulations and other materials provided to the IT department by various university services. Thematic blocks of situations should be separated from each other, between them the logic of interaction is revealed. Then it is necessary to describe the structure and functionality of the knowledge base, which must be broadcast to young people. It is necessary to develop a system for evaluating employees, determine the final requirements for the system architecture, then determine all locations on which the actions will unfold, assign roles and detail all the scenarios in steps in the following sequence: task - step number - step (user action), scoring for completing a task (optional, if there is an evaluation system) - fine (optional) - scene (location) - objects used in logic - sound effect according to the script or the logic for reproducing it (optional) - special effects (optional) comment (that the operator should do if any). It is advisable to involve undergraduates in the humanities department of the university in writing scripts.

\section{ON THE WAY TO THE "SMART UNIVERSITY"}

The university needs a creative atmosphere: only in it will the generation of ideas, projects important for the outside world and for the university itself take place.

The creative atmosphere at the university can be created only by non-standard forms of work with modern youth using innovative means of information transfer. So, digital educational technologies solve five key problems: 1) financial affordability of education for the poor; 2) the expansion of choice: it is possible to search for a better course, a better teacher, overcoming provincialism; 3) learning complex skills that are not available in reality (VR and stimulants, role-playing games), solving problems that arise suddenly; 4) adaptation to the abilities and interests of a person through digital educational and methodological complexes; 5) game format (content teams, online training) [16].

I would like to note once again that there is no conflict between online and traditional education. No online platform can replace fundamental science. The student teacher personal contact is important and unique; a set of effective online tools should be added to it, thus combining traditional and digital education. Education will only benefit from big data. With the help of artificial intelligence, students will receive more tools in different life circumstances.

The university of modernity should have a smart IT infrastructure that allows it to overcome geographical boundaries. Information resources are constantly used by a large number of internal (students, teachers, employees) and external (applicants, partners, government) consumers. Equipping with intelligent systems will give the university the status of an expert center, the center of the city and region. Intellectualization of the university is the most important task that requires comprehensive solutions, for example, the decisions on data storage, access to it and its security are the first priority. It is necessary to determine the clear contours of the Smart University system, describe the basic requirements for the system and the classification of smart services at a university. Creating smart IT services at a university requires the development of a multi-component model. The system will provide connections between students, teachers, employees, applicants, partners, the IoT network will unite various devices interacting with each other, equipped with sensors. The transition to smart infrastructure at the university will affect all university services: administrative, educational, international and other activities will be covered. The university will gain a smart building, where an electronic access system to educational buildings and dormitories, a 
[8] R. Sun, Y. J. Wu, Q. Cai, «The effect of a virtual reality learning environment on learners' spatial ability», Virtual Reality, 2019, V. 23, Issue 4, pp. 385398

[9] L. Daniela, M. D. Lytras, «Editorial: Themed Issue on Enhanced Educational Experience in Virtual and Augmented Reality», Virtual reality, 2019, V.23, Issue 4, pp. 325-327

[10] Y. Vasseghian, A. Bahadori, A. Khataee, «Modeling the Interfacial Tension of Water-Based Binary and Ternary Systems at High Pressures Using a Neuro-Evolutive Technique", ACS OMEGA, 2019, V.5, Issue 1, pp. 781-790

[1] B. Plester, C. Wood,"Exploring Relationships Between Traditional and New Media Literacies: British Preteen Texters at School", Journal of ComputerMediated Communication, 2009, 14 (4), pp. 11081129.

[2] T.L. Chernysheva The use of innovative digital technologies in the educational process of the university // Proceedings of the International Scientific and Practical Conference on Digital Economy (ISCDE 2019): Atlantis Press Series: Advances in Economics, Business and Management Research, 2019, Volume 105, pp. 585-589.

[3] H. Willis, "Digital Media, Culture and Education: Theorizing Third Space Literacies/Worried About the Wrong Things: Youth, Risk, and Opportunity in the Digital World/Create to Learn: Introduction to Digital Literacy." Afterimage, 2017, V. 45, no. 2/3, pp. 60-62.

[4] M.U. Sattar; S. Palaniappan; A. Lokman, «Motivating Medical Students Using Virtual Reality Based Education», International Journal of Emerging Technologies in Learning, 2020, V.15, Issue 2, pp. 160174

[5] J. P. Richards, A. J. Done, S. R. Barber, «Virtual coach: the next tool in functional endoscopic sinus surgery education», International Forum of Allergy and Rhinology, 2020, V. 10 Issue 1, pp. 97-102

[6] T. Luiz, D. Lerner, D. Schnier, «Virtual Simulation Environment for Medical Training», Ercim News, 2020, V.120, pp. 26-27

[7] G. Makransky, S. Borre - Gude, R. E. Mayer, «Motivational and cognitive benefits of training in immersive virtual reality based on multiple assessments», Journal of Computer Assisted learning, 2019, V. 35, Issue 6, pp. 691-707
[11] S. Kim, R. Heo, Y. Chung, "Virtual Reality Visualization Model (VRUM) of the Tricarboxylic Acid (TCA) Cycle of Carbohydrate Metabolism for Medical Biochemistry Education», Journal of Science Education and Technology, 2019, V. 28, Issue 6, pp. $602-612$

[12] Z. Yang, Y. Wang, «Analysis of the rock stratum in a mining area in China with virtual reality technology», Geotechnical research, 2019, V. 6, Issue 4, pp. 288-293

[13] Reality Management System, Varwin, URL: https://varwin.com/, Retrieved 19.01.2020

[14] «How Virtual Reality Helps Business», IHODI, URL: https://ru.ihodl.com/analytics/2019-08-22/kakvirtualnaya-realnost-pomogaet-biznesu/, Retrieved 09.01.2020

[15] T.L. Chernysheva, «The Third Mission of the University: Technologies for the Formation of Thinking in Modern Students, Novosibirsk: NSTU Publishing house, 2020, p.160

[16] «Online learning: How it Changes the Structure of Education and the Economy of the University», URL: https://vo.hse.ru/data/2015/09/28/1073772954/Kusmino v.pdf, Retrieved 17.12.2019 